\title{
On the deviations of Ampère's theory of magnetism from the theory of the electromagnetic forces
}

\section{J. Stefan}

To cite this article: J. Stefan (1879) On the deviations of Ampère's theory of magnetism from the theory of the electromagnetic forces, Philosophical Magazine Series 5, 8:46, 83-84, DOI: $10.1080 / 14786447908639655$

To link to this article: http://dx.doi.org/10.1080/14786447908639655

曲 Published online: 13 May 2009.

Submit your article to this journal $[\pi$

Џll Article views: 3

Q View related articles $\longleftarrow$ 
from lengthening, it shortens ; instead of decreasing, its resistance to ruplure and the intensity augment; and the light gently redescends to resume and keep its place at the extremity of the carbons. If, on the contrary, the current should increase, the arc bends and becomes concave towards the carbons; but, its tendency to ascend counterbalancing the action of the directing current, it never stretches enough to break. The best economic conditions are at tained when this curve is just pronounced enough to prevent the ascensional movement of the light. In this case the unavoidable noise of the electric light is reduced to its minimum, because the amplitudes of the vibratory motion are the smallest possible.

In brief, the burner which I submit to the Academy, with its points beneath, realizes considerable advantages:-(1) that of simplicity, since it needs no mechanism and requires no preliminary preparation; the whole amonnts to a support and some carbons; (2) that of mechanical economy, since the number of the flames is almost doubled; (3) increase of light, since each of the new foci is nearly twice as effective as the old ones; (4) the quality of the light, which is whiter; (5) a more advantageous disposition of the foci, which direct their greatest sum of light downwards, where it is of use, instead of losing it skywards, where it would be useless; (6) lastly, economy of the combustible, since in proportion to the size of the carbons the consumption is less. All this constitutes for the electric light a sensible advance, and cannot fail to enlarge the place it has already taken in public lighting, thanks to the improvement of the engines, to the carbons of $\mathbf{M}$. Carré, and to $\mathbf{M}$. Jabloschkoff's candle.-Comptes Rendus de l'Académie des Seiences, A pril 28, 1879, t. lxxxviii. pp. 829-832.

\section{ON THE DEVIATIONS OF AMPÈR'S THEORY OF MAGNETISM FROM}

THE THEORY OF THE ELECTROMAGNETIC FORCES. BY J. STEFAN.

The divergences between the two theories stand out most clearly when the moments with which a current-element tends to rotate an elementary magnet are determined according to both. According to the electromagnetic theory, the current-element rotates the magnet out of the plawe when both stand perpendicular to the line joining them and are situated in the same plane; while according to Ampère it cannot act at all upon the elementary current equivalent to the magnet, since it stands perpendicular to every part of the latter and at the same time to the connecting lines leading to them.

If the current-element falls into the connecting line, according to the electromagnetic theory it exerts no rotating action upon the magnet; but according to Ampère it sets the equivalent elementary current continuously rotating about its axis-an action which is quite foreign to the electromagnetic theory.

If the magnet lies in the direction of line of conjunction, a current-element perpendicular to this, according to both theories, rotates the magnet out of the plane, but according to Ampère's theory with a moment twice as great as according to the electromagnetic: 
For closed circuits the differences compeusate one another, but the parts which the individual elements of the circuit have in the total action are different. Thus, according to the electromagnetic theory the elements of the vertical circuit of a tangent-compass all act with equal deflecting force upon the very short needle; according to Ampère the elements situated in the vertical diameter exert no action, while those in the horizontal diameter act twice as powerfully as according to the other theory.

In the memoir the electromagnetic is compared with the general electrodynamic theory, which also assumes transversally-acting forces, and was developed by the author in his memoir "On the Fundamental Formulw of Electrodynamies," published in vol. lix. of the Sitzungsberichte of the Academy (1869).

The comparison has reference, first, to the forces, and, secondly, to the pairs of forces, which a current-element exerts upon an elementary current. In the former respect Ampère's theory, and all those which also assume transversal forces, though of such a nature that they cannot move the common centre of gravity of two current-elements, agree with the electromagnetic theory. In the second respect the electromagnetic theory corresponds only with Grassmann's. But as these two theories differ in the expressions for the forces, there is not any electrodynamic theory containing in itself the electromagnetic. With the exception of Grassmann's, all the theories contain, though not in like manner, continuous rotations of the magnets by the action of the component of the current-element in the connecting-line.-Kaiserliche Akademie der Wissenschaften in Wien, math.-naturu. Classe, April 17, 1879, pp. $110,111$.

\section{ON THE PRODUCTION OF BARIUM FROM BARIUM-AMALGAM.} BY JULIUS DONATH, OF GRAZ.

In this note we are informed that the amalgamated barium easily obtained by Crookes's method, by digesting solution of barium chloride with sodium-amalgam, does not after distillation contain any pure barium at all, but leaves only an analgam rich in barium, which may contain $62-77$ per cent. of mercury.

It was already mentioned by Bunsen that the barium- or calciumamalgam that appears at the amalgamated platinum electrode in the electrolysis of aqueous solution of chloride of barium or calcium respectively, also obstinately retains mercury.

In all probability $\mathbf{S}$. Kern's method, viz. heating oxide and iodide of barium with sodium, extracting with quicksilver, and distilling, will yield no better result. All the statements about the silverywhite metallic lustre of barium must evidently be referred to the amalgam. Pure barium, as obtained by Bunsen and Matthiessen by electrolysis of the fused chloride, is bronze-coloured. This colour, it is true, is sometimes exhibited by the most superficial layers of the barium-rich amalgam, which under the action of a very elevated temperature have been deprived of mercury ; but even such portions of the amalgam are grey on the inside, and in water they leave considerable traces of mercury.-Keiserl. Akad. d. Wissensch. in Wien, math,-naturu. Classe, 1879, No. X. p. 109. 